\title{
Surgical bypass in malignant afferent loop syndrome
}

\author{
Krystal Tan, Zi Qin Ng 두, Suresh Navadgi
}

General Surgery, Royal Perth Hospital, Perth, Western Australia, Australia

Correspondence to Dr Zi Qin Ng; kentng@hotmail.co.uk

Accepted 5 August 2021

\section{DESCRIPTION}

A 68-year-old man presented with 1-day history of increasing right-sided abdominal pain with associated nausea and vomiting. His medical history includes a delayed presentation of empyema of the gallbladder requiring percutaneous cholecystostomy tube and interval laparoscopic subtotal cholecystectomy in 2017. He presented a few months later with cholangitis and Endoscopic retrograde cholangiopancreatography (ERCP) showing a distal common bile duct (CBD) stone and incidental mid-CBD external compression with brushings confirming cholangiocarcinoma. He required a Whipple's procedure for clearance of margins in 2017. The histopathology identified pT3N0M1 with metastatic disease at the excised cholecystotomy tube tract. He received pseudoadjuvant chemoradiotherapy. A recent PET scan in February 2021 demonstrated evidence of metastatic disease at the anterior abdominal wall, adjacent to the gastrojejunostomy (GJ) site.

On arrival, he was cholangitic. Examination of the abdomen revealed tenderness at the right side of the abdomen. His liver function test showed an obstructive picture. He was resuscitated and intravenous antibiotics was commenced. The CT demonstrated small bowel obstruction proximal to the GJ site (figure 1A,B) with intrahepatic duct dilatation (figure 2A,B), in keeping with afferent loop syndrome (ALS).

The gastroenterologist attempted to pass the guidewire through the afferent limb for endoscopic stenting but was unsuccessful as there was complete obstruction of the afferent limb. He proceeded with an upper midline laparotomy. Intraoperatively, there was moderate adhesions from prior surgery

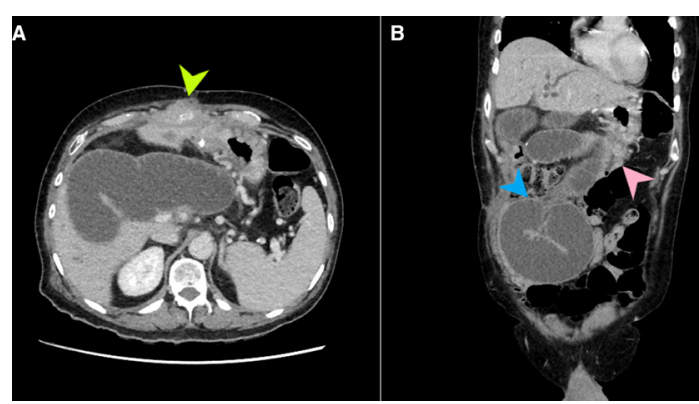

Figure 1 (A) Axial slice of the CT scan showing dilated small bowel loop at the afferent limb with the transition at the gastrojejunal anastomosis and evidence of metastatic disease (green arrow). (B) coronal slice of the CT scan showing the dilated small bowel loops proximal to the gastrojejunal anastomosis (blue arrow) and collapse of small bowel loops at the efferent limb (pink arrow).

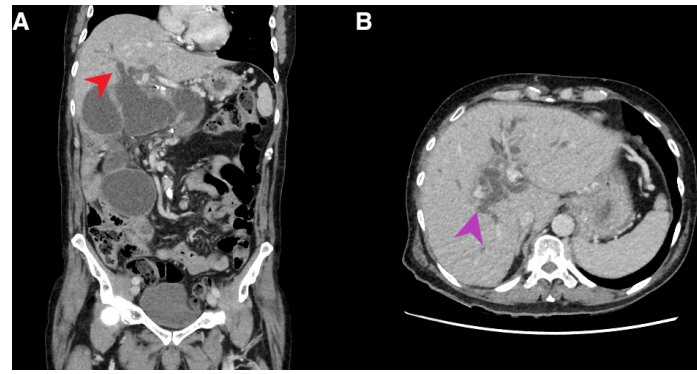

Figure 2 (A) Coronal slice of the CT scan showing the afferent loop syndrome leading to dilatation of the hepaticojejunostomy anastomosis (red arrow) and (B) axial slice of the CT scan showing intrahepatic duct dilatation (purple arrow).

and evidence of small volume peritoneal metastatic disease. A limited adhesiolysis was performed to allow identification of the dilated afferent limb and collapsed efferent limb. A Braun side-to-side handsewn enteroenterostomy bypass was constructed between the afferent and efferent limbs. He recovered well and was discharged on day 5 postoperatively. He remained well on last clinic follow-up at 3 months and currently is receiving palliative chemoradiotherapy.

ALS is a mechanical obstruction proximal to, or at the site of, the gastrojejunal anastomosis. Procedures most associated with ALS include gastrectomy with Billroth II or Roux-en-Y reconstruction, and pancreaticoduodenectomy. ${ }^{1}$

It has a reported incidence rate of $0.3 \%-1 \%$. However, a retrospective cohort study has reported an incidence rate of $13 \%$ following pancreatoduodenectomies (majority secondary to radiation enteropathy). ${ }^{2}$ Common causes included postoperative adhesion leading to compression or kinking in the afferent limb, stenosis due to ulceration at the gastrojejunal anastomosis site, radiation enteritis of the afferent loop and local tumour recurrence. Other intraluminal causes include internal hernias, volvulus, intussusception, enteroliths, bezoars and foreign bodies. ${ }^{124}$

ALS can present with non-specific symptoms. Patients often have acute abdominal pain, nausea and vomiting, obstructive jaundice and cholangitis. ${ }^{35}$ Increased intraluminal pressure results in the accumulation of enteric, biliary and pancreatic secretions leading to obstructive jaundice, acute pancreatitis or ascending cholangitis.

CT scan remains the mainstay diagnostic study of choice. ${ }^{1}$ Management is guided by the underlying aetiology and long-term prognosis. When present acutely, initial management is focused on resuscitation and initiation of antibiotics. Traditionally, surgery has been the primary option with either 
adhesiolysis and reconstruction for benign causes; or bypass and/ or reconstruction for malignant causes. Recently, endoscopic and radiological interventions have emerged as forms of alternative palliative management. These include endoscopic stent placement, Endoscopic ultrasound (EUS)-guided gastroenterostomy/ enteroenterostomy, transhepatic percutaneous enteral stenting or cholangiography for biliary drainage.

When endoscopic or percutaneous intervention has failed for the management of malignant ALS, further operative management needs to be thoroughly discussed with the patient due to its associated morbidity and mortality. Often these patients are frail and malnourished with disseminated disease, a limited palliative Braun entero-entero bypass surgery is preferred over resection and reconstruction of the gastrojejunal anastomosis. ${ }^{5}$

In summary, in this case, based on the preoperative imaging findings from the positrion emission tomography (PET) scan and CT scans (dilated proximal small bowel loops to the gastroenterostomy with dilated hepaticojejunostomy and intrahepatic ducts) and clinical presentation of cholangitis, it was clear that

\section{Learning points}

Early recognition of afferent loop syndrome (ALS) is crucial.

- Those presenting with a known history upper gastrointestinal tract reconstructive surgery with signs of small bowel obstruction, sepsis and jaundice should raise a suspicious for ALS.

- Management options depend on the patient's overall condition and long-term prognosis. the metastatic disease at the anterior abdominal wall adjacent to the GJ was causing ALS. Least invasive procedures such as endoscopic stenting should first be attempted but failed in this instance. Any operative intervention should be limited to bypass surgery rather than major resection and reconstructive surgery given the associated morbidity and poor long-term prognosis from metastatic pancreatic cancer.

Contributors $\mathrm{KT}$ : data collection and drafting of manuscript. ZQN: study design and review of manuscript. SN: codesign study and critical review of manuscript. All authors approved the final version of manuscript for submission and publication.

Funding The authors have not declared a specific grant for this research from any funding agency in the public, commercial or not-for-profit sectors.

Competing interests None declared.

Patient consent for publication Obtained.

Provenance and peer review Not commissioned; externally peer reviewed.

ORCID iD

Zi Qin Ng http://orcid.org/0000-0002-6272-4640

\section{REFERENCES}

1 Blouhos K, Boulas KA, Tsalis K, et al. Management of afferent loop obstruction: reoperation or endoscopic and percutaneous interventions? World J Gastrointest Surg 2015;7:190-5.

2 Desai A, Manvar A, Ho S. Afferent loop syndrome due to volvulus of the afferent limb. ACG Case Rep J 2019;6:e00123.

3 Pannala R, Brandabur JJ, Gan S-I, et al. Afferent limb syndrome and delayed GI problems after pancreaticoduodenectomy for pancreatic cancer: single-center, 14-year experience. Gastrointest Endosc 2011;74:295-302.

4 Katagiri H, Tahara K, Yoshikawa K, et al. Afferent loop syndrome after Roux-en-Y total gastrectomy caused by volvulus of the Roux-Limb. Case Rep Surg 2016;2016:4930354

5 Adoor D, Smith ZL. Percutaneous- and EUS-guided gastroenterostomy for malignant afferent limb syndrome. VideoGIE 2020;5:542-4.

Copyright 2021 BMJ Publishing Group. All rights reserved. For permission to reuse any of this content visit

https://www.bmj.com/company/products-services/rights-and-licensing/permissions/

BMJ Case Report Fellows may re-use this article for personal use and teaching without any further permission.

Become a Fellow of BMJ Case Reports today and you can:

- Submit as many cases as you like

- Enjoy fast sympathetic peer review and rapid publication of accepted articles

- Access all the published articles

- Re-use any of the published material for personal use and teaching without further permission

Customer Service

If you have any further queries about your subscription, please contact our customer services team on +44 (0) 2071111105 or via email at support@bmj.com.

Visit casereports.bmj.com for more articles like this and to become a Fellow 